\title{
Ensaios preliminares sobre autofecundação e cruzamentos no melhoramento do capim-elefante ${ }^{1}$
}

\author{
Maria da Conceição Silva ${ }^{2 *}$, Mércia Virginia Ferreira dos Santos ${ }^{3,7}$, Mário de Andrade Lira ${ }^{4}$, \\ Alexandre Carneiro Leão de Mello ${ }^{3}$, Erinaldo Viana de Freitas ${ }^{5}$, Ramilton Jader Menezes \\ Santos $^{6}$, Rinaldo Luiz Caraciolo Ferreira ${ }^{3,7}$
}

\footnotetext{
${ }^{1}$ Pesquisa financiada parcialmente pelo CNPq e pelo acordo IPA/UFRPE.

2 Programa de Pós-graduação em Zootecnia - UFRPE.

3 Departamento de Zootecnia - UFRPE.

4 IPA.

5 IPA, PDIZ-UFRPE.

${ }^{6}$ Curso de graduação. Bolsista FACEPE.

${ }^{7}$ Bolsista CNPq.
}

RESUMO - Objetivou-se nesta pesquisa verificar a possibilidade do uso da autofecundação no melhoramento do Pennisetum purpureum e comparar progênies de Pennisetum purpureum obtidas por três formas de fecundação (tratamentos): autofecundação, cruzamentos intraespecíficos e cruzamentos interespecíficos com Pennisetum glaucum. Foram avaliadas 10, 2 e 2 famílias com um total de, respectivamente, 160 progênies provenientes de cruzamento intraespecífico, 38 progênies de cruzamento interespecífico e 40 progênies de autofecundação. Foram realizadas duas avaliações para determinar a produção de matéria seca - MS (kg/touceira), o teor de MS (\%), a altura de planta (m), o perfilhamento basilar ( $\mathrm{n}^{\circ}$ /touceira) e índice de sobrevivência (\%), em parcelas sem repetição. Os tratamentos cruzamento intraespecífico, cruzamento interespecífico e autofecundação apresentaram as respectivas médias de 0,47; 0,78 e 0,46 e de 0,14; 0,23 e 0,22 kg de MS/touceira, respectivamente, na primeira e segunda avaliações. Experimentos com parcelas repetidas devem ser conduzidos visando isolar os efeitos de meio dos efeitos genéticos. O cruzamento interespecífico mostrou-se promissor na geração de genótipos com porcentagem de MS adequada ao processo de ensilagem. Todos os tratamentos apresentaram potencial para liberar variabilidade nos caracteres avaliados, entretanto, o baixo índice de sobrevivência das progênies provenientes da autofecundação dificulta a obtenção de linhas puras.

Palavras-chave: caracteres produtivos, clones, depressão endogâmica, híbrido, teor de matéria seca, sobrevivência

\section{Preliminary tests on self-pollination and crossbreed in elephantgrass breeding}

\begin{abstract}
The objectives of this work were to evaluate the self-pollination as a tool in the elephantgrass (Pennisetum purpureum) breeding and to compare progenies of Pennisetum purpureum origined from different breeding strategies: self-pollination, intraspecific crossbreeds, and interspecific crossbreeds with Pennisetum glaucum. The experimental treatments were represented by the three fecundation forms: intraspecific crossbreed, interspecific crossbreed and self-pollination. A total of ten families originated from intraspecific crossbreed resulting in 160 progenies; two families originated from interspecific crossbreed resulting in 38 progenies, and two families originated from selfpollination resulting in 40 progenies, was evaluated. The evaluated traits were dry matter production (kg/tussock), dry matter concentration (\%), plant height (m), number of basal tillers (n./tussock) and survival index (\%), in two evaluations and non-replicated plots. The intraspecific crossbreed, interspecific crossbreed and self-pollination presented average dry matter production of $0.47,0.78$, and $0.46 \mathrm{~kg}$ of DM/tussock, at first evaluation and $0.14,0.23$, and $0.22 \mathrm{~kg}$ of DM/ tussock, at second evaluation, respectively. This indicates the necessity of plot replication to separate the environmental effect from the genetic effect. The interspecific crossbreed showed potential to generate progenies with satisfactory dry matter concentration which is more appropriated for ensiling. The treatments showed potential to release variability of traits evaluated through vegetative propagation, however, the low survival index of self-pollinated progenies reduces the probability of obtaining pure lines of elephantgrass.
\end{abstract}

Key Words: clones, dry matter concentration, endogamyc depression, hybrid, productive traits, survival

Este artigo foi recebido em 15/2/2006 e aprovado em 31/8/2007. 


\section{Introdução}

O melhoramento genético vegetal proporcionou importantes conquistas produtivas nas últimas décadas (Borém, 2001). No milho, por exemplo, destaca-se o desenvolvimento de híbridos superiores, que foram gerados com a utilização de uma fase endogâmica (obtenção, seleção e avaliação de linhas puras) e posterior hibridação das linhas selecionadas (Comstock, 1949).

Neste sentido, a endogamia é utilizada para concentrar genes favoráveis para, em seguida, recombiná-los na hibridação (Allard, 1971). A obtenção de linhas puras em capim-elefante (Pennisetum purpureum Schum) segue raciocínio análogo. O método também pode ser utilizado visando liberar variabilidade fixadas pela multiplicação clonal, conforme processo adotado na obtenção do cv. Mott (Sollenberger \& Jones Jr., 1989).

A endogamia em plantas pode ocasionar, entre outras conseqüências, o aparecimento de anormalidades e plantas de reduzida altura e produtividade, bem como a perda generalizada de vigor (Borém, 2001). Estas conseqüências são atribuídas à depressão endogâmica, causada pelo aumento da homozigose, a qual atinge máxima expressividade com a autofecundação de linhas puras (Stringfield, 1950).

Existem, portanto, diferenças quanto aos efeitos causados pela endogamia em plantas autofecundadas, que englobam desde ausência ou baixa perda de vigor, como nas Cucurbitáceas, até efeitos drásticos, como na Medicago sativa, onde poucas linhagens sobrevivem além da terceira geração de autofecundação (Allard, 1971). A abóbora (Cucurbita spp.) autofecundada por 10 anos apresentou apenas crescimento vegetativo reduzido (Lower \& Edwards, 1986), porém, em capim-elefante, observam-se plantas de baixo vigor (Pereira et al., 2001). Por outro lado, este baixo vigor das plantas oriundas da autofecundação do capimelefante possibilitou selecionar o cultivar Mott, indicado para utilização sob pastejo, por ser de porte baixo (Sollenberger \& Jones Jr., 1989). Neste contexto, a autofecundação desta espécie pode ser utilizada visando liberar variabilidade fixada pela multiplicação clonal.

O capim-elefante tem número básico cromossômico igual a sete, tendo evoluído como um alotetraplóide ( $2 n=4 x=28)$, com comportamento diplóide normal (Brunken, 1977), sendo seu germoplasma composto por ecotipos, clones, variedades e híbridos interespecíficos (Gonzalez \& Menezes, 1982). A espécie apresenta protogenia de três a quatro dias e pode ser propagada via rizoma, haste ou semente. O Pennisetum purpureum Schum pode ser cruzado com o Pennisetum glaucum (L.) Leeke (Hanna,
1994), formando híbridos triplóides, que, após ter seu conjunto cromossômico duplicado, origina híbridos férteis hexaplóides.

Diante do exposto, este trabalho foi conduzido com os objetivos de verificar a possibilidade do uso da autofecundação no melhoramento do Pennisetum purpureum e comparar progênies de Pennisetum purpureum obtidas por uma autofecundação e por cruzamentos intraespecífico e interespecífico com Pennisetum glaucum.

\section{Material e Métodos}

O teste foi conduzido na Estação Experimental de Itambé-PE, pertencente à Empresa Pernambucana de Pesquisa Agropecuária (IPA).

O município de Itambé está localizado na microrregião fisiográfica da Mata Seca do Estado de Pernambuco, com

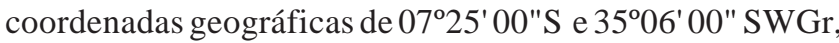
altitude de $190 \mathrm{~m}$, pluviosidade anual média de $1.300 \mathrm{~mm}$, temperatura anual média de $25,1^{\circ} \mathrm{C}$ e clima sub-úmido megatérmico, segundo a classificação de Thornthwaite (CPRH, 2003). Os índices pluviométricos registrados no período de avaliação encontram-se na Tabela 1.

Os solos predominantes na estação são classificados como Podzólicos Vermelho-Amarelo, com horizonte A proeminente de textura argilosa, fase floresta sub-caducifólia e relevo ondulado (Embrapa, 1999).

O resultado da análise química do solo revelou $\mathrm{pH}=4,76 ;$ P disponível $=12,5 \mathrm{mg} / \mathrm{kg} ; \mathrm{Ca}=1,12 \mathrm{cmol}_{\mathrm{c}} / \mathrm{dm}^{3}$; $\mathrm{Mg}=0,95 \mathrm{cmol}_{\mathrm{C}} / \mathrm{dm}^{3} ; \mathrm{Na}=0,04 \mathrm{cmol}_{\mathrm{C}} / \mathrm{dm}^{3} ; \mathrm{K}=0,12 \mathrm{cmol}_{\mathrm{C}} / \mathrm{dm}^{3} ;$ $\mathrm{Al}=1,47 \mathrm{cmol}_{\mathrm{C}} / \mathrm{dm}^{3} ; \mathrm{H}=10,98 \mathrm{cmol}_{C} / \mathrm{dm}^{3} ; \mathrm{S}=2,25 \mathrm{cmol}_{\mathrm{C}} / \mathrm{dm}^{3}$;

Tabela 1 - Valores de precipitação mensal e anual de 2003, 2004 e 2005

\begin{tabular}{lrrr}
\hline Mês & \multicolumn{3}{c}{ Precipitação $(\mathrm{mm})$} \\
\cline { 2 - 4 } & 2003 & 2004 & 2005 \\
\hline Janeiro & 38,9 & 242,6 & 4,0 \\
Fevereiro & 209,0 & 230,8 & 29,6 \\
Março & 165,4 & 74,4 & 76,0 \\
Abril & 82,0 & 193,2 & 49,2 \\
Maio & 143,2 & 209,4 & 216,6 \\
Junho & 353,4 & 297,0 & 4,63 \\
Julho & 167,6 & 299,0 & 77,8 \\
Agosto & 73,6 & 72,6 & 171,6 \\
Setembro & 62,0 & 50,8 & 28,8 \\
Outubro & 48,2 & 9,0 & 24,8 \\
Novembro & 86,6 & 7,0 & 11,0 \\
Dezembro & 71,6 & 10,0 & 22,0 \\
\hline Anual & $1.501,5$ & $1.704,2$ & 716,0 \\
\hline
\end{tabular}

Fonte: Estação Experimental do IPA em Itambé-PE. 
CTC $=14,7 \mathrm{cmol}_{\mathrm{c}} / \mathrm{dm}^{3} ; \mathrm{V}=15,5 \%$ e $\mathrm{m}=40 \%$ na camada de 0 -20 $\mathrm{cm}$ de profundidade.

Inicialmente, o solo recebeu 3,0 t/ha de calcário dolomítico, visando corrigir e elevar a saturação de bases para $60 \%$, e adubação equivalente a $100 \mathrm{~kg} / \mathrm{ha}$ de $\mathrm{K}_{2} \mathrm{O}$ na forma de cloreto de potássio, $60 \mathrm{~kg} / \mathrm{ha} \mathrm{P}_{2} \mathrm{O}_{5}$ na forma de superfosfato triplo e $50 \mathrm{~kg}$ de N/ha na forma de uréia, sendo o último aplicado na fase inicial de crescimento das plantas (15 dias pós-corte).

Os tratamentos foram representados pelas três formas de fecundação: autofecundação e cruzamentos intraespecífico e interespecífico (sendo obtidos híbridos interespecíficos triplóides) (Tabela 2).

A autofecundação foi representada por duas famílias, uma proveniente do cultivar Guaçu 122 e a outra do Cuba 116. A escolha destes cultivares deveu-se ao êxito na obteção de progênies em detrimento dos cultivares Taiwan A-146, Pusa Napier/472-72 e Roxo de Botucatu também autofecundados.

Foram avaliadas 10 famílias com um total de 160 progênies provenientes de cruzamento intraespecífico, duas famílias com um total de 38 progênies de cruzamento interespecífico e duas famílias com um total de 40 progênies de autofecundação.

O plantio foi realizado em $06 / 2002$ por meio de duas frações de colmo/cova com duas gemas/fração, em espaçamento de $1,0 \mathrm{~m} \times 1,0 \mathrm{~m}$, onde as plantas permaneceram em crescimento livre até a realização do corte rente ao solo para uniformização, ocorrido em 3/2003.

Foram realizados dois cortes a $40 \mathrm{~cm}$ do solo e aos 60 dias de crescimento das plantas para determinar produção de matéria seca - MS (kg/touceira), teor de MS (\%), altura de planta $(\mathrm{m})$ e perfilhamento basilar ( $\mathrm{n}^{\circ} /$ touceira). No período de 3/2003 a 5/2005, determinou-se o índice de

Tabela 2 - Cruzamentos utilizados com respectivo número de progênies obtidas

\begin{tabular}{|c|c|c|}
\hline \multirow[t]{2}{*}{ Número de progênies } & \multicolumn{2}{|c|}{ Cruzamento } \\
\hline & Taiwan A-146* & $\times$ Guaçu 122* \\
\hline 23 & Pusa Napier ou 472-76* & × Guaçu 122* \\
\hline 07 & Pusa Napier ou 419-76* & $\times$ Guaçu 122* \\
\hline 10 & Cuba $116 *$ & × Guaçu 122* \\
\hline 08 & Roxo de Botucatu* & $\times$ Guaçu 122* \\
\hline 22 & Taiwan A-146* & $\times$ Cuba $116^{*}$ \\
\hline 15 & Pusa Napier ou 472-76* & $\times$ Cuba 116* \\
\hline 10 & Pusa Napier ou 419-76* & $\times$ Cuba 116* \\
\hline 10 & Guaçu 122* & $\times$ Cuba $116^{*}$ \\
\hline 27 & Roxo de Botucatu* & $\times$ Cuba $116^{*}$ \\
\hline 06 & Pennisetum glaucum** & $\times$ Guaçu 122* \\
\hline 32 & Pennisetum glaucum** & $\times$ Cuba $116^{*}$ \\
\hline
\end{tabular}

* Cultivares de Pennisetum purpureum Schum; ** milheto. sobrevivência (\%). A primeira avaliação ocorreu em 30/05/2003 e a segunda, em 30/09/2004, após novo corte de unifomização rente ao solo. Na ocasião do segundo corte de uniformização (30/07/2004), o solo foi adubado com uréia, cloreto de potássio e superfosfato triplo, nas mesmas dosagens aplicadas inicialmente.

No período entre as avaliações deste trabalho, as plantas foram submetidas a cortes mais frequentes, visando atender outro propósito do referido programa de melhoramento não incluído neste trabalho, sendo realizada, após cada corte, uma adubação equivalente a $50 \mathrm{~kg}$ de N/ha na forma de uréia.

Vale mencionar que estas progênies eram constituintes da fase 1 do programa de melhoramento de plantas forrageiras proposto por Valle \& Souza (1995), as quais totalizavam 472 progênies com vários caracteres sob avaliação (Silva, 2006), motivo pelo qual, apesar de a repetição ser um dos princípios da experimentação (Gomes, 1985), optou-se por trabalhar com parcelas não-repetidas.

A altura de planta foi obtida com auxílio de uma fita métrica, representando o comprimento da planta desde o solo até o ápice da folha mais alta que não apresentava curvatura. O perfilhamento basilar foi determinado pela contagem do número de perfilhos basilares/touceira.

O teor de MS foi obtido por meio da secagem $\left(65^{\circ} \mathrm{C}\right)$ de três perfilhos/parcela. A produção de matéria verde foi obtida pelo corte total da touceira, sendo a produção de matéria verde multiplicada pelo teor de MS, para obtenção da produção de MS/touceira.

O índice de sobrevivência foi determinado em dois momentos: setembro/2004 e maio/2005. A razão obtida ao dividir o número de plantas vivas/família nestes períodos pelo número de plantas vivas/família no início das observações (março/2003), expressa em porcentagem, representou o índice de sobrevivência nos respectivos períodos mencionados.

Os dados foram submetidos a uma análise estatística descritiva, na qual se determinaram o intervalo de confiança para média e a freqüência para os diferentes caracteres avaliados (Gomes, 1985), por meio do programa computacional Excel.

\section{Resultados e Discussão}

Os híbridos intraespecíficos, interespecíficos e autofecundados apresentaram valores médios, dentro dos intervalos de confiança, de 0,47; 0,78 e 0,46 kg de MS/ touceira, respectivamente, no primeiro corte (Tabela 3).

Independentemente do tratamento, as produções de MS do segundo corte foram inferiores $(\mathrm{P}<0,05)$ às obtidas 
no primeiro corte (Tabela 3), fato que pode ser atribuído aos diferentes índices de precipitação pluviométrica registrados nos distintos períodos de avaliação (Tabela 1). Ainda na avaliação de setembro/2004, observa-se que os híbridos intraespecíficos foram produtivamente inferiores $(\mathrm{P}<0,05)$ aos interespecíficos e às progênies $S_{1}$ (autofecundação).

No geral, o melhor desempenho produtivo dos híbridos interespecíficos pode ser conseqüência do benefício gerado ao cruzar uma espécie de elevado potencial produtivo como o capim-elefante com uma rústica como o milheto (Schank \& Chynoweth, 1993).

A autofecundação em capim-elefante origina plantas de baixa produtividade e tamanho inferior, como conseqüência da redução da heterozigose nesta espécie (Hanna, 1994). Entretanto, vale lembrar que, em espécies tetraplóides como o capim-elefante (Brunken, 1977), a redução da heterozigose com uma autofecundação é de apenas 5,6\% (Borém, 2001), fazendo com que os efeitos negativos decorrentes da endogamia na $\mathrm{S}_{1}$ quanto à produção de $\mathrm{MS}$ sejam de baixa magnitude (Tabela 3 ).

Diante da existência de variabilidade entre progênies oriundas de autofecundação, torna-se possível selecionar genótipos com menor depressão endogâmica (Genter \& Alexander, 1966) ou com características desejáveis, conforme procedimento adotado na seleção do cultivar Mott (Sollenberger \& Jones Jr., 1989).

Expressões heteróticas e endogâmicas de caracteres quantitativos, como produção de MS, devem ser explicadas com base na natureza e na magnitude dos efeitos gênicos que as controlam (Finkner et al., 1981), o que não foi abordado neste trabalho.

O Taiwan A-146 encontra-se entre os quatro mais produtivos de sete cultivares de capim-elefante avaliados por Botrel et al. (1994). Conforme curva de crescimento em 196 dias, a aproximadamente $250 \mathrm{~mm}$ e sob temperatura média de $15^{\circ} \mathrm{C}$, o Taiwan A-146 apresentou produtividade biológica de 22,99 g de MS/dia/m² (Andrade \& Gomide, 1971). Considerando esta produtividade, estima-se produtividade de $1,38 \mathrm{~kg} / \mathrm{m}^{2} / 60$ dias.
Apesar de as médias apresentadas na Tabela 3 terem sido inferiores à produtividade mencionada, as freqüências apresentadas na Figura 1 demonstram a existência de híbridos interespecíficos (Figura 1C) e S1 de capimelefante (Figura 1E) produzindo entre 1,1 e 1,6 kg de $\mathrm{MS} / \mathrm{m}^{2} / 60$ dias. Vale mencionar que, mesmo havendo redução de $102 \mathrm{~mm}$ de chuvas (Tabela 1) na fase de crescimento das plantas (agosto-setembro/2004), quando comparada à fase de crescimento das plantas (abril-maio/ 2003), foi possível constatar genótipos de superior PMS (Figuras 1B, 1D e 1F) em setembro/2004, o que pode indicar que esses genótipos podem ser alternativas para áreas do estado que apresentam índices pluviométricos menores que os registrados na Zona-da-Mata.

Nas duas avaliações, o maior teor de MS $(\mathrm{P}<0,05)$ foi apresentado pelos híbridos interespecíficos, com valores médios, dentro dos intervalos de confiança, de 27,51 e 26,09\% de MS na avaliação realizada em maio/2003 e setembro/2004, respectivamente (Tabela 3).

O menor $(\mathrm{P}<0,05)$ teor de MS $(\%)$ foi apresentado pelos híbridos intraespecíficos, com médias de 21,99 e $22,21 \%$, respectivamente, na primeira e segunda avaliações (Tabela 3). Teores de MS ainda mais baixos, variando entre 16,65 e 19,11\%, são comumente encontrados em capim-elefante aos 60 dias (Lavezzo et al., 1983).

O baixo teor de matéria desta gramínea acarreta inúmeros problemas quando ensilado (Gordon, 1967), caracterizando-se, principalmente, em perdas por efluentes e por fermentações indesejáveis (Murk \& Shinners, 2001). Neste sentido, práticas como emurchecimento e/ou uso de aditivos de baixa umidade têm sido utilizadas para elevar a MS para teores acima de 30\% (Vilela \& Wilkinson, 1987). Este teor de MS, quando associado a adequado teor de carboidratos solúveis (Tosi et al., 1992), garante boa fermentação lática (Balsalobre et al., 2001).

Por outro lado, a possibilidade de se selecionarem genótipos de Pennisetum sp. com teor de MS acima de $30 \%$ (Figura 2 ) pode ser mais uma alternativa na viabilização do uso desta gramínea na forma de silagem.

Tabela 3 - Intervalo de confiança (IC) para média da produção de matéria seca (PMS) e do teor de matéria seca (\% MS) de progênies de Pennisetum sp. obtidas por diferentes formas de fecundação, Itambé-PE

Forma de fecundação

Períodos de avaliação

\begin{tabular}{lccccr}
\cline { 2 - 3 } & \multicolumn{2}{c}{ Maio/2003 } & & \multicolumn{2}{c}{ Setembro/2004 } \\
\cline { 2 - 3 } \cline { 5 - 6 } & PMS (kg/touceira) & MS (\%) & & PMS kg/touceira) & MS (\%) \\
\hline Cruzamento intraespecífico & $0,47 \pm 0,02$ & $21,99 \pm 0,38$ & & $0,14 \pm 0,01$ & $22,21 \pm 0,25$ \\
Cruzamento interespecífico & $0,78 \pm 0,00$ & $27,51 \pm 1,64$ & & $0,23 \pm 0,02$ & $26,09 \pm 0,48$ \\
Autofecundação & $0,46 \pm 0,15$ & $24,06 \pm 0,36$ & & $0,22 \pm 0,06$ & $24,16 \pm 0,43$ \\
\hline
\end{tabular}

IC $(0,95)$ = intervalo de confiança para média com nível de confiança de $95 \%$ de probabilidade. 
A

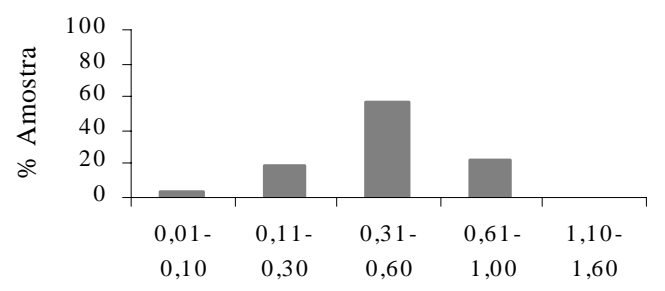

PMS (kg/touceira)

C

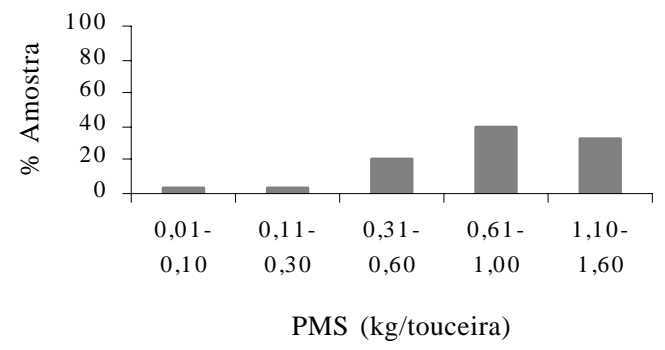

E

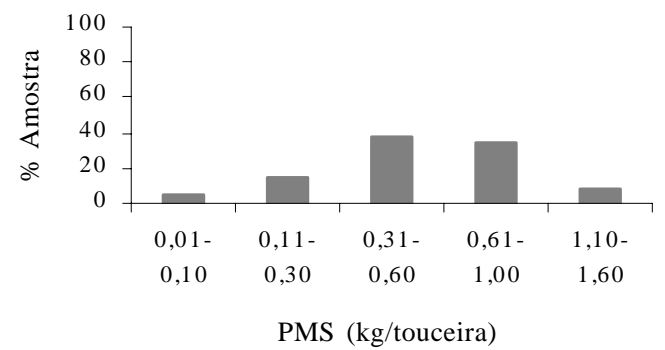

B

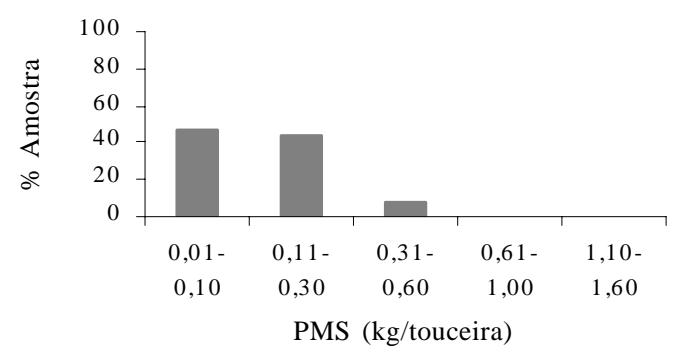

$\mathrm{D}$

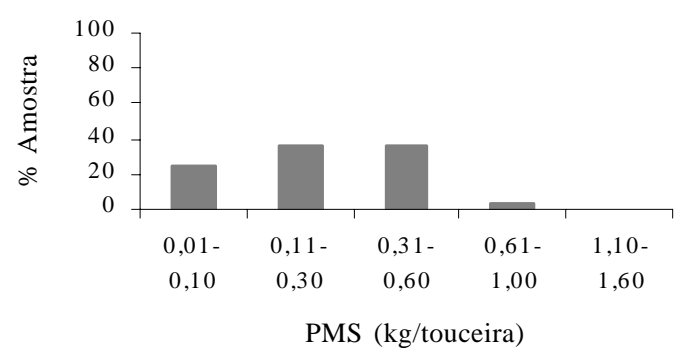

F

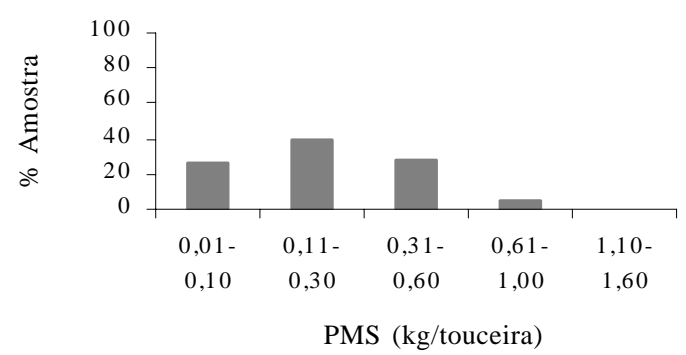

Figura 1 - Distribuições das freqüências das progênies obtidas com cruzamentos intraespecíficos, A (05/2003) e B (09/2004); interespecíficos, C (05/2003) e D (09/2004); e uma autofecundação, E (05/2003) e F (09/2004), quanto à produção de matéria seca (PMS).

Aproximadamente 20\% dos híbridos interespecíficos apresentaram teor de MS entre 30 e 33\% nos dois períodos de avaliação (Figuras 2C e 2D).

O maior teor de MS dos híbridos de capim-elefante com o milheto, quando comparados a outros tipos de progênies de capim-elefante, pode estar associado ao precoce florescimento destes genótipos (Silva, 2006), indicando precoce maturidade dos mesmos. Entretanto, vale mencionar que o milheto apresenta baixa qualidade quando atinge a maturidade (Gates et al., 1995).

A seleção de clones de Pennisetum sp. para teor de MS deve ser associada a análises para determinação de fibra em detergente neutro (FDN), fibra em detergente ácido (FDA) e padrões de fermentação das silagens confeccionadas com clones de diferentes teores de MS.
Diferenças observadas entre as freqüências da primeira (Figuras 2A, 2C e 2E) e segunda (Figuras 2B, 2D e 2F) avaliações demonstram que, na seleção de clones de Pennisetum sp. para \% MS, há a necessidade de se avaliar o referido caráter em diferentes épocas do ano, com maior número de cortes e utilizando delineamento experimental, para possibilitar, inclusive, a estimação de parâmetros genéticos.

As progênies oriundas de autofecundação apresentaram a maior $(\mathrm{P}<0,05)$ média, dentro dos intervalos de confiança, para perfilhamento basilar na primeira avaliação, enquanto na segunda avaliação este tratamento não diferiu $(\mathrm{P}<0,05)$ dos híbridos interespecíficos (Tabela 4).

Nos dois períodos de avaliação, os tratamentos apresentaram médias próximas a 20 perfilhos basilares/ 
A

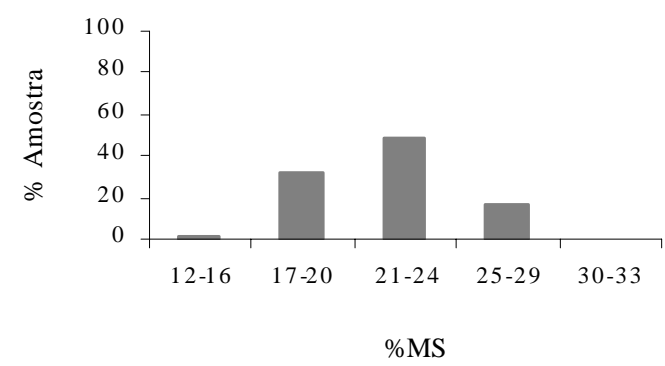

C

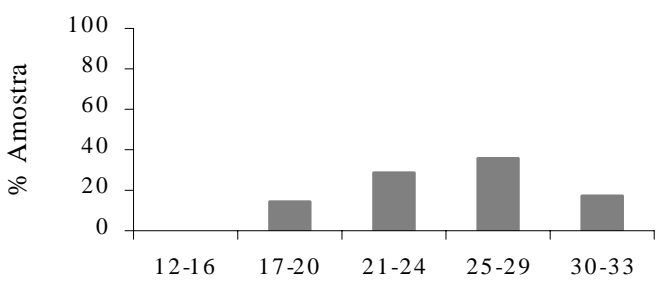

\%MS

E

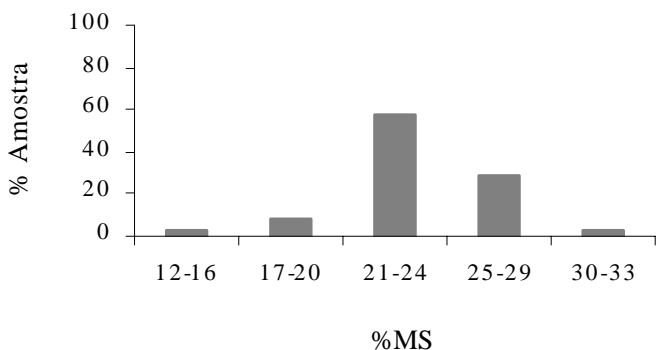

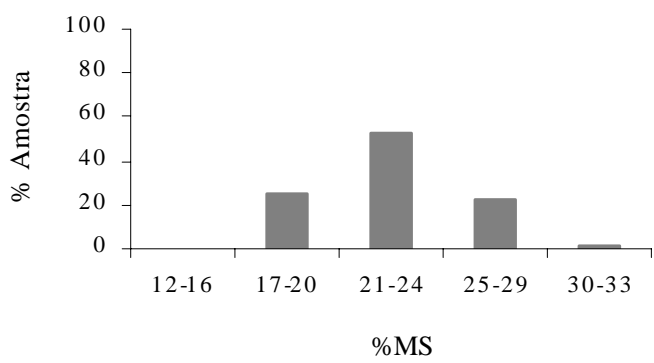

D

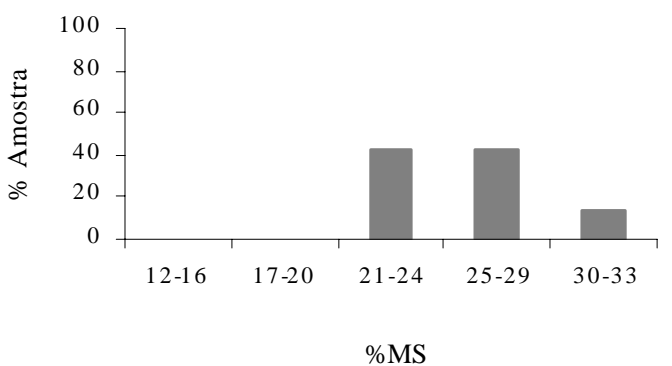

F

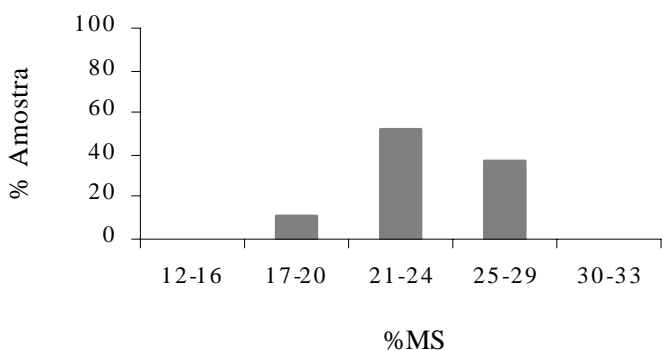

Figura 2 - Distribuições das freqüências das progênies obtidas com cruzamentos intraespecíficos, A (05/2003) e B (09/2004); interespecíficos, C (05/2003) e D (09/2004); e uma autofecundação, E (05/2003) e F (09/2004), quanto ao teor de matéria seca (MS).

touceira ou 20 perfilhos $/ \mathrm{m}^{2}$. Entretanto, existe variabilidade dentro dos tratamentos para o referido caráter (Figura 3).

O perfilhamento basilar pode apresentar variabilidade entre cultivares: Taiwan A-146 (26 perfilhos $\left./ \mathrm{m}^{2}\right)$ e Mott (121 perfilhos $/ \mathrm{m}^{2}$ ) sob as mesmas condições (Botrel et al., 1994); entre épocas do ano: época seca (27,25 perfilhos $\left./ \mathrm{m}^{2}\right)$ e época chuvosa (55,56 perfilhos $\left./ \mathrm{m}^{2}\right)$ em uma mesma coleção de plantas (Silva, 2001); ou conforme o manejo de corte adotado (Santos et al., 2003).

Os híbridos interespecíficos apresentaram as maiores $(\mathrm{P}<0,05)$ médias para altura de plantas, ao passo que as progênies provenientes de autofecundação, as menores nas duas avaliações (Tabela 4).

$\mathrm{Na}$ avaliação realizada em setembro/2004, todos os tratamentos apresentaram médias para altura de plantas inferiores às obtidas na avaliação de maio/2003, sendo esta redução de 36,63\% nos híbridos intraespecíficos, de 39,83\% nos híbridos interespecíficos e de 14,84\% nas progênies de autofecundação.

Resposta diferenciada entre genótipos aos efeitos de ambiente tem sido constatada em várias espécies de plantas cultivadas, comportamento que influencia os ganhos genéticos e dificulta a recomendação de um mesmo genótipo para ambientes distintos (Marchioro et al., 2003). Especificamente, quando ocorre interação genótipo $\times$ ambiente temporário, torna-se necessário aumentar o número de medidas, visando reduzir este componente na expressão do caráter (Cruz \& Regazzi, 1997).

O comportamento das progênies dentro de cada tratamento revela que, na primeira avaliação (Figuras 4A, 4C e 4E), apenas os híbridos interespecíficos apresentaram mais de 
50\% de suas progênies na faixa máxima de altura registrada (2,4 a 3,0 m). Entretanto, vale ressaltar que uma característica como altura só é fixada na quinta geração (Borém, 2001).

As freqüências apresentadas para altura de planta nas Figuras 4B, 4D e 4F, referentes à avaliação realizada em setembro/2004, demonstram que as plantas cresceram menos neste período do que em maio/2003 (Figuras 4A, 4C e 4E), provavelmente, pela redução dos índices pluviométricos, ocorrendo comportamento similar ao da produção de MS.

Tabela 4 - Intervalo de confiança (IC) para a média do perfilhamento basilar (PB) e da altura de plantas (AP) de diferentes tipos de progênies de Pennisetum sp., Itambé-PE

\begin{tabular}{lcccc}
\hline Forma de fecundação & \multicolumn{2}{c}{ Períodos de avaliação } \\
\cline { 2 - 4 } & \multicolumn{2}{c}{ Maio/2003 } & \multicolumn{2}{c}{ Setembro/2004 } \\
\cline { 2 - 4 } & PB (No/touceira) & AP (m) & PB (No/touceira) \\
\hline Cruzamento intraespecífico & $21,04 \pm 0,18$ & $2,02 \pm 0,03$ & $17,29 \pm 0,96$ \\
Cruzamento interespecífico & $18,27 \pm 0,05$ & $2,36 \pm 0,02$ & $1,28 \pm 0,01$ \\
Autofecundação & $22,20 \pm 0,96$ & $1,55 \pm 0,21$ & $22,36 \pm 1,05$ & $1,42 \pm 0,01$ \\
\hline
\end{tabular}

IC $(0,95)$ = Intervalo de confiança para média com nível de confiança de 95\% de probabilidade.

A

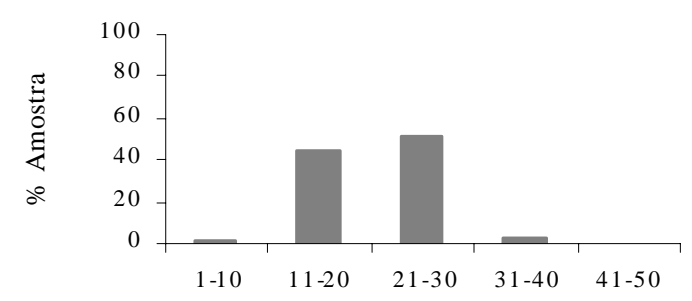

Perfilhamento basilar (no/touceira)

C

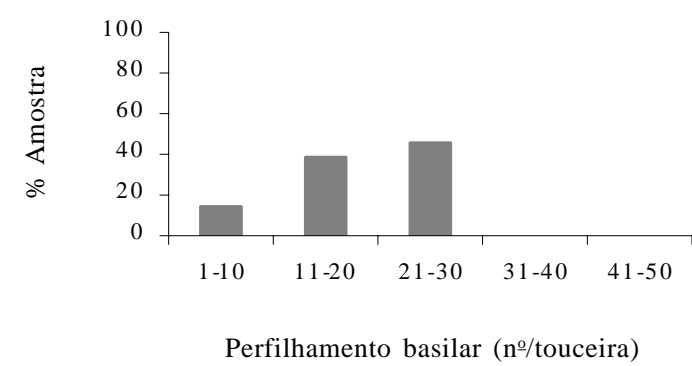

E

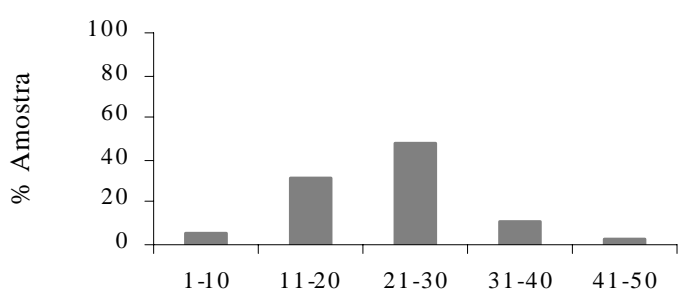

Perfilhamento basilar (nº/touceira)
B

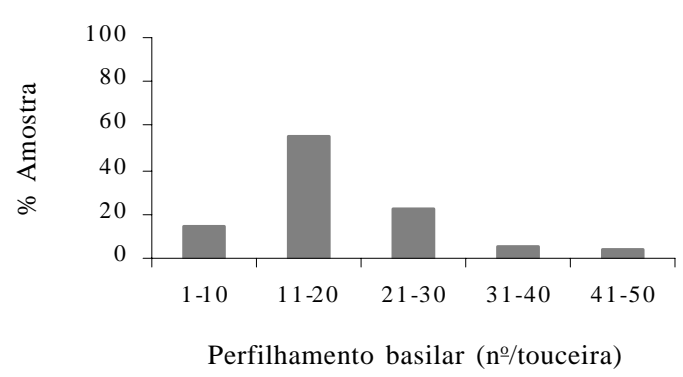

D

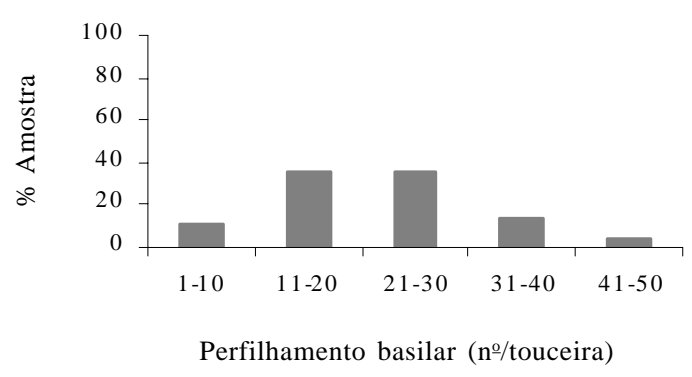

$\mathrm{F}$

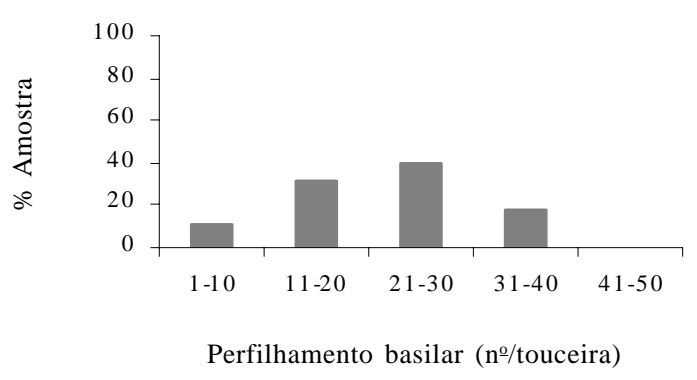

Figura 3 - Distribuições das freqüências das progênies obtidas com cruzamentos intraespecíficos, A (05/2003) e B (09/2004); interespecíficos, C (05/2003) e D (09/2004); e uma autofecundação, E (05/2003) e F (09/2004), quanto ao perfilhamento basilar. 
A

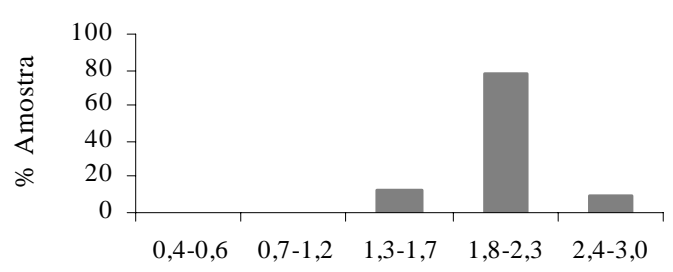

Altura de plantas (m)

C

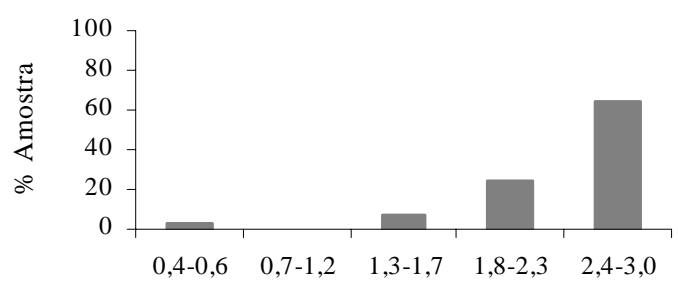

Altura de plantas (m)

E

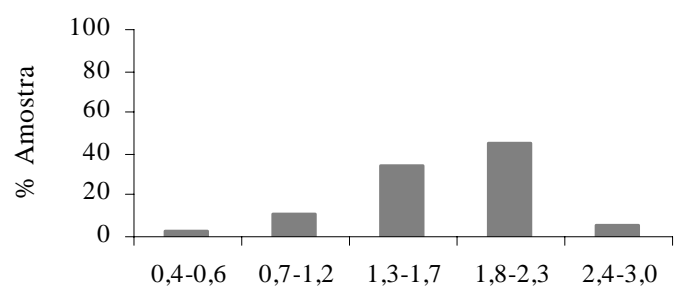

Altura de plantas (m)
B

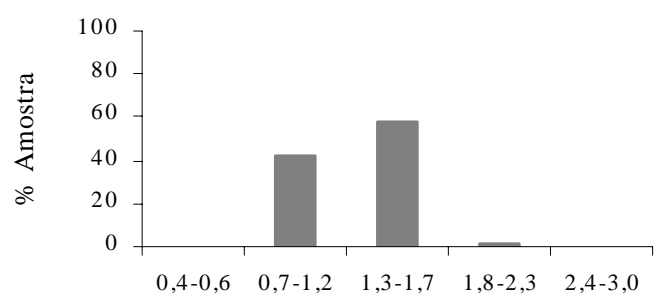

Altura de plantas (m)

$\mathrm{D}$

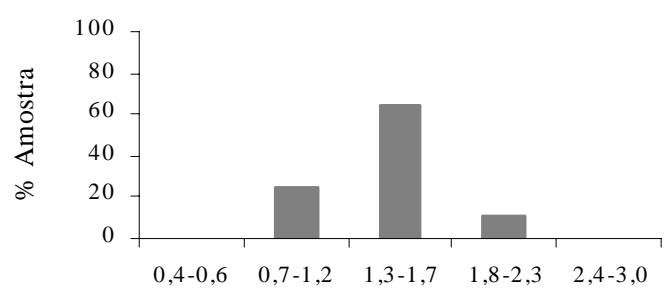

Altura de plantas (m)

F

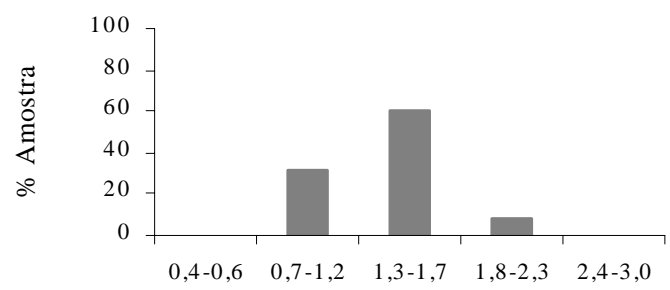

Altura de plantas (m)

Figura 4 - Distribuições das freqüências das progênies obtidas com cruzamentos intraespecíficos, A (05/2003) e B (09/2004); interespecíficos, C (05/2003) e D (09/2004); e uma autofecundação, E (05/2003) e F (09/2004), quanto à altura de plantas.

Na avaliação de setembro/2004, o índice de sobrevivência das progênies foi superior a $89 \%$ em todos os tratamentos avaliados (Tabela 5). Não houve diferença $(P>0,05)$ entre as progênies obtidas pelas distintas formas de cruzamento (intraespecífica e interespecífica). As progênies provenientes de autofecundação apresentam o menor $(\mathrm{P}<0,05)$ índice de sobrevivência, quando comparadas aos demais tipos de progênies, entretanto, a diferença entre o maior e o menor índice de sobrevivência, dentro dos intervalos de confiança, foi de apenas 6,47\%.

Na última avaliação realizada (maio/2005) para determinar apenas o índice de sobrevivência das plantas, observaram-se médias de 56,47; 76,15 e 13,34\% para as progênies oriundas de cruzamentos intraespecíficos, cruzamentos interespecíficos e autofecundação, respectivamente.
Ainda na avaliação realizada em maio/2005 (Tabela 5), observa-se que a média do índice de sobrevivência encontrada para as progênies provenientes de autofecundação oscila para mais ou para menos 9\%. Este resultado se deve ao fato de as progênies obtidas com uma autofecundação do cultivar Cuba 116 apresentarem índice de sobrevivência de 26,68\% e das progênies obtidas com uma autofecundação do cultivar Guaçu 122, de $0,00 \%$.

O elevado índice de mortalidade em plantas oriundas de autofecundação do capim-elefante deve-se ao baixo vigor das mesmas, decorrente do processo de depressão endogâmica (Pereira et al., 2001). Entretanto, índices de mortalidade de 43,53 e 20,85\% das progênies oriundas de cruzamentos intraespecíficos e interespecíficos, respectivamente, também são elevados. Provavelmente, estes 
Tabela 5 - Intervalo de confiança (IC) para o índice de sobrevivência (\%) de progênies de Pennisetum sp. em diferentes períodos de avaliação, Itambé-PE

\begin{tabular}{lcc}
\hline Forma de fecundação & \multicolumn{2}{c}{ Índice de sobrevivência (\%) } \\
\cline { 2 - 3 } & $03 / 2003$ a & $03 / 2003$ a \\
$09 / 2004$ & $05 / 2005$ \\
\hline Cruzamento intraespecífico & $94,90 \pm 1,28$ & $56,47 \pm 3,95$ \\
Cruzamento interespecífico & $92,19 \pm 2,80$ & $79,15 \pm 0,35$ \\
Autofecundação & $89,83 \pm 0,12$ & $13,34 \pm 8,99$
\end{tabular}

IC $(0,95)=$ intervalo de confiança para média com nível de confiança de $95 \%$ de probabilidade.

resultados são conseqüências de estresse hídrico sofrido pelas plantas entre outubro de 2004 e janeiro de 2005, em que se registraram apenas $39 \mathrm{~mm}$ de chuva (Tabela 1 ).

\section{Conclusões}

A autofecundação do capim-elefante apresenta potencial para liberar variabilidade, fixada pela multiplicação clonal, em todos os caracteres avaliados.

Existe variabilidade dentro das famílias obtidas pelas diferentes formas de fecundação para os caracteres avaliados.

O cruzamento interespecífico mostrou-se promissor na geração de genótipos com teor de MS adequado ao processo de ensilagem.

Nos clones advindos de cruzamento intraespecífico, cruzamento interespecífico e autofecundação, foram constatados clones desejáveis quanto à produção de MS e ao perfilhamento basilar.

A autofecundação em capim-elefante afeta negativamente a sobrevivência das plantas.

O baixo índice de sobrevivência em progênies de capimelefante autofecundado dificulta a obtenção de linhas puras.

\section{Agradecimento}

À Universidade Federal Rural de Pernambuco e à equipe de campo da Estação Experimental de Itambé, pertencente à Empresa Pernambucana de Pesquisa Agropecuária (IPA), pelo apoio recebido. Aos alunos da Pós-graduação em Zootecnia que participaram da coleta de dados.

\section{Literatura Citada}

ALLARD, R.W. Princípios do melhoramento genético de plantas. São Paulo: Edgard Blucher, 1971. 381p.

ANDRADE, I.F.; GOMIDE, J.A. Curva de crescimento e valor nutritivo do capim-elefante (Pennisetum purpureum Schum) 'A-146 Taiwan'. Revista Ceres, v.100, n.18, p.431-447, 1971.

BALSALOBRE, M.A.A.; NUSSIO, L.G.; MARTHA JR., G.B. Controle de perdas na produção de silagens de gramíneas. In:
SIMPÓSIO DE PASTAGEM, 2001, Piracicaba. Anais... Piracicaba: Sociedade Brasileira de Zootecnia, 2001. p.890911.

BORÉM, A. Melhoramento de plantas. Viçosa, MG: Universidade Federal de Viçosa, 2001. 300p.

BOTREL, M.A.; ALVIM, M.J.; MARTINS, C.E. Avaliação e seleção de cultivares de capim-elefante (Pennisetum purpureum Schum) para pastejo. Revista Brasileira de Zootecnia, v.23, n.5, p.754-762, 1994.

BRUNKEN, J. Systematic survey of Pennisetum sect. Pennisetum (Graminae). American Journal of Botany, v.64, n.2, p.161176, 1977.

COMSTOCK, R.E. A breeding procedure designed to make maximum use of both general and specific combining ability. Agronomy Journal, v.41, n.8, p. 360-367, 1949.

CRUZ, C.D.; REGAZZI, A.J. Modelos biométricos aplicados ao melhoramento genético. Viçosa, MG: Universidade Federal de Viçosa, 1997. 390p.

EMPRESA BRASILEIRA DE PESQUISA E AGROPECUÁRIA EMBRAPA. Sistema brasileiro de classificação de solos. Brasília: Embrapa Produção de Informações, Rio de Janeiro: Embrapa Solos, 1999. 412p.

COMPANHIA PERNAMBUCANA DO MEIO AMBIENTE - CPRH. Diagnóstico sócio-ambiental do litoral Norte de Pernambuco. Recife: 2003. 214p.

FINKNER, R.E.; FINKNER, M.D.; GLAZE, R.M. et al. Control for percentage grain protein and grain yield in grain sorghum. Crop Science, v.21, p.139-142, 1981.

GATES, R.N.; HANNA, W.W.; GASCHO, G.J. [1995]. Evaluation of grain pearl millet plant components. Disponível em: http://www.ads.uga.edu/annrpt/1995/ 95/_104.htm. Acesso em: 20/1/2006

GENTER, C.F.; ALEXANDER, M.W. Development and selection of productive $\mathrm{S}_{1}$ inbred lines of corn (Zea mays L.). Crop Science, v.6, p.429-431, 1966.

GOMES, P.F. Curso de estatística experimental. São Paulo: Nobel, 1985. 466p.

GONZALEZ, D.A.; MENEZES, G. O capim-elefante. Zootecnia, v.20, n.4, p.229-259. 1982.

GORDON, C.H. Storage losses in silage as affectd by moisture content and structure. Journal Dairy Science, v.50, n.3, p.397-403, 1967.

HANNA, W.W. Elephantgrass improvement. In: SIMPÓSIO SOBRE CAPIM-Elefante, 2., 1994, Coronel Pacheco. Anais... Coronel Pacheco: EMBRAPA-CNPGL, 1994. p.73-81. 1994.

LAVEZZO, W.; GUTIERREZ, L.C.; SILVEIRA, A.C. et al. Utilização do capim-elefante (Pennisetum purpureum Schum), cultivares Mineiro e Vruckwona, como plantas para ensilagem. Revista Brasileira de Zootecnia, v.12, n.1, p.163-176, 1983.

LOWER, R.L.; EDWARDS, M.D. Cucumber breeding. In: BASSETT, M.J. (Ed.) Breeding vegetable crops. Westport: AVI Publication, 1986. p.173-204.

MARCHIORO, V.S.; CARVALHO, F.I.F.; OLIVEIRA, A.C. et al. Expressão do fenótipo em populações de aveia conduzidas em diferentes ambientes. Ciência Rural, v.33, n.4, p.651-656, 2003.

MURCK, R.E.; SHINNERS, K.J. Conserved forage (silage nd hay) progress and priorities. In: INTERNATIONAL GRASSLANDS CONGRESS, 19., 2001, São Pedro. Proceedings ... São Pedro: 2001. p.753-762.

PEREIRA, A.V.; VALLE, C.B.; FERREIRA, R.P. et al Melhoramento de forrageiras tropicais. In: NASS, L.L.; VALOIS, A.C.C.; MELO, I.S. et al. (Eds.) Recursos genéticos e melhoramento-plantas. Rondonópolis: Fundação MT, 2001. p.549-602.

SANTOS, M.V.F.; DUBEUX JR., J.C.B.; SILVA, M.C. et al. Produtividade e composição química de gramíneas tropicais na Zona da Mata de Pernambuco. Revista Brasileira de Zootecnia, v.32, n.4, p.821-827, 2003. 
SCHANK, S.C.; CHYNOWETH, D.P. The value of triploid, tetraploid dand hexaploid napiergrass derivatives as biomass and (or) forage. Tropical Agriculture, v.70, p.83-87, 1993.

SILVA, A.L.C. Avaliação e seleção de clones de capim-elefante (P. purpureum Schum) para pastejo na Zona da Mata de Pernambuco. Recife: Universidade Federal Rural de Pernambuco, 2001. 111p. Dissertação (Mestrado em Zootecnia) - Universidade Federal Rural de Pernambuco, 2001.

SILVA, M.C. Avaliação de descritores morfológicos e seleção de diferentes tipos de progênies de Pennisetum $s p$. Recife: Universidade Federal Rural de Pernambuco, 2006. 85p. Tese (Doutorado em Zootecnia) - Universidade Federal Rural de Pernambuco, 2006.

SOLLENBERGER, L.E.; JONES JR., C.S. Beef production from nitrogen-fertilized Mott dwarf elephantgrass Pensacola bahiagrass pastures. Tropical Grasslands, v.23, p.129-134, 1989.
STRINGFIELD, G.H. Heterozygosis and hybrid vigor in maize. Agronomy Journal, v.42, n.2, p.145-152, 1950.

TOSI, H.; ITURRINO, R.P.S.; FURTADO, C.E. et al. Avaliação química e microbiológica do capim-elefante, cultivar Taiwan A-148, preparado para ensilagem com bagaço de cana-deaçúcar. Pesquisa Agropecuária Brasileira, v.27, n.10, p.1409-1413, 1992.

VALLE, C.B.; SOUZA, F.H.D. Construindo novas cultivares de gramíneas forrageiras para os cerrados brasileiros. In: REUNIÃO ANUAL DA SOCIEDADE BRASILEIRA DE ZOOTECNIA, 32. 1995, Brasília. Anais... Brasília: Sociedade Brasileira de Zootecnia, 1995, p. 3-7.

VILELA, D.; WILKINSON, J.M. Efeito do emurchecimento e da adição da areia sobre a fermentação e digestibilidade in vitro do capim-elefante (Pennisetum purpureum, Schum) ensilado. Revista Brasileira de Zootecnia, v.16, n.6, p.550$562,1987$. 